\title{
NESTING OF THE GREAT GRAY OWL IN MANITOBA
}

\author{
by David F. Parmelee, Department of Biology,
} Kansas State Teachers College, Emporia, Kansas

In the early evening of June 3 , 1964, Phil Reader and I visited a small clearing upgrown to tall aspens deep in a muskeg, several miles southwest of Lake Atikameg (Clearwater) near The Pas, Manitoba, where Goshawks (Accipiter gentilis) had nested in previous times. We failed to find the hawks but were amazed to see a brooding Great Gray Owl (Strix nebulosa) on an old hawk nest some 50 feet up in one of the largest trees. It was the first nesting bird of its kind either of us had seen. Reader had resided on this land for many years.

By the time I had climbed halfway to the nest, the adult had flushed and alighted in another tree. In the unlined nest were two fairly large but still downy young of different sizesindicating an age difference of two or three days. The adult, probably female, returned to the young soon after I had climbed down to the ground again. No large hawks or other species of owls were noted in the vicinity, although a pair of Sparrow Hawks (Falco sparverius) and a Common Goldeneye (Bucephala clangula) had nests in aspens near by.

The following day we returned to the owl site with H. A. Stephens and Jack Simmons and spent several hours watching and photographing the brooding bird. The mate, after first announcing his arrival by hooting softly, flew from the muskeg directly to the nest with a small rodent. Upon presenting the prey, he quickly flew back to the muskeg on perfectly silent wings and disappeared only to return a short time later. Both birds were decidedly tame-almost indifferent to our presence. We did not have an opportunity to check the nest again, but presumably the young fledged. Reader has since checked the nesting site each spring. The owls did not

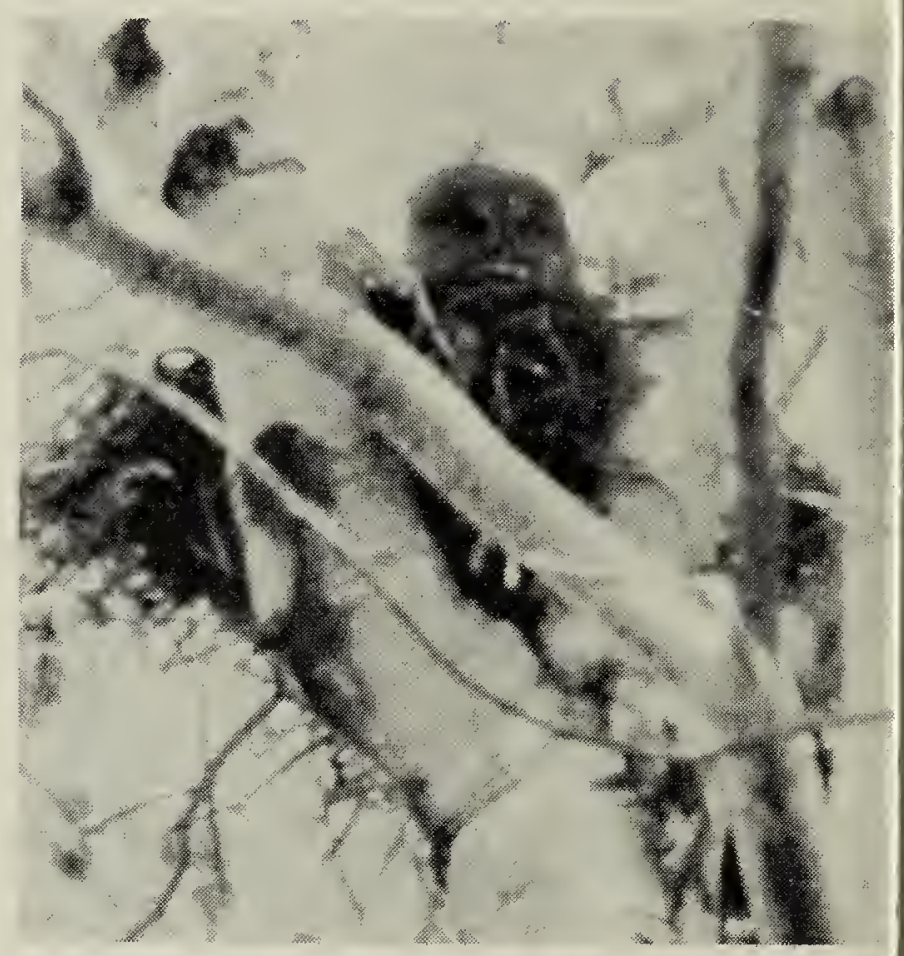

return to this nest in the next three years nor were any Great Gray Owls seen in the general area. In 1968, however, a pair has occupied the same nest (pers. corres., R. W. Nero).

These owls may not have been the only ones nesting in the vicinity of The Pas in 1964, for early on the morning of June 3 that year I had flushed a Great Gray Owl from the muskeg immediately west of the Evergreen Lodge on Lake Atikameg. Owner of the lodge, Russ Tawse, later told us that the bird (or birds) had been seen rather frequently at the dump a short distance away. I do not believe that this bird, or pair, occupied the nest on the Reader property.

According to Robert W. Nero (pers. corres.), the nesting described above is the second one of the Great Gray Owl for Manitoba. E. Robinson reported finding a nest with three young on the east side of Lake Dauphin on May 14, 1926 (Blue Jay, 12:20; "Chickadee Notes" No. 271, June 3: 1926). Observations were made when the author was engaged in research for the University of Oklahoma Medical Center (National Institutes of Health Grant No. AI 05232-01). 
